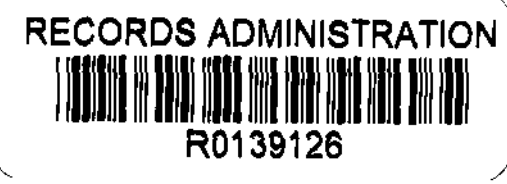

DP-1537

R0139126

TIS FILE

RECORD COPY

\title{
COMPUTER CONTROL FOR \\ A CLADDING THICKNESS TESTER
}

R. J. SAND

DECEMBER 1979

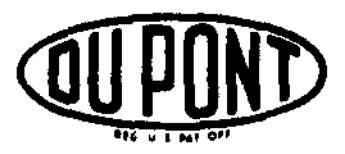

E. I. du Pont de Nemours \& Co. (Inc.) Savannah River Laboratory Aiken, South Carolina 29801 


\section{bHeclatmer}

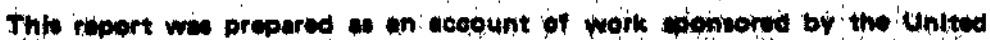

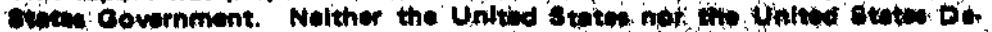

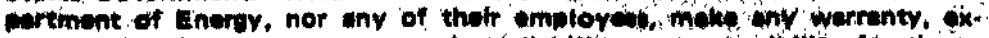

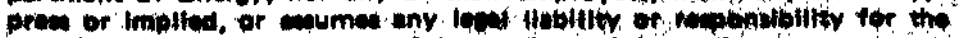

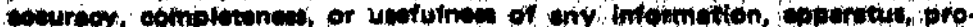

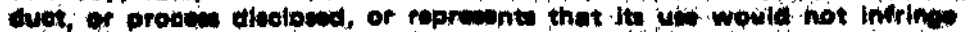

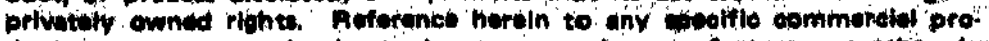

duet, procem, or wrvios by trade name, mert, minufectuxer, of othorwin.

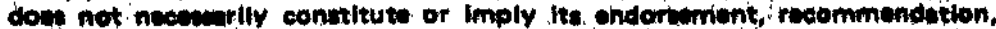

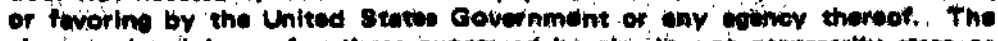

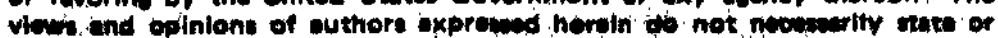

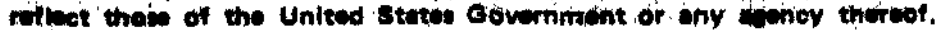

Printed in the United Stetes of Americe

$$
\text { Avalioble from }
$$

National Technlcal Information service

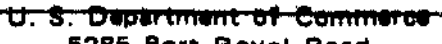

5285 Port Royal Road

Springfleld, Virginia 22161

Price: Printed Copy A02; Microficho AO1 


\title{
COMPUTER CONTROL FOR
}

\section{A CLADDING THICKNESS TESTER}

\author{
R. J. SAND
}

Approved by

D. Baker, Jr, , Research Manager

Laboratory Operations and Services

DECEMBER 1979

E. I. du Pont de Nemours \& Co. (Inc.) Savannah River Labora'tory Aiken, South Carolina 29801 


\section{ABSTRACT}

A cladding thickness tester for extruded reactor fuel tubes has been automated to provide reduced operator interaction. The cladding thickness tester, which uses an $x$-ray fluorescence analyzer, has been interfaced with an SRL/6800 microcomputer to control fuel tube orientation, operate the analyzer, calculate cladding thickness, and give pertinent data in hardcopy tabular form. 
Introduction 5

Cladding Thickness Tester SRL/6800 Microcomputer 5

Software 7

CTT Program Structure 10

Hardware $\quad 10$

References $\quad 11$

1 Cladding Th1ckness Tester 6

2 Spectfication Entry 8

3 Data Output 9

4 Program Structure 11 


\section{INTRODUCTION}

The Nuclear Engineering Division has a cladding thickness tester (CTT) for nondestructive thickness determination of experimental and production fuel tubes. As designed, the CTT did not allow precise position control of the tubes and required three analyses to be performed by the operator. A Savannah River Laboratory (SRL)/6800 microcomputer has been included in the CTT to precisely position the tubes and automatically make the analyses, thereby reducing any human errors in measuring techniques.

The CTT uses a Kevex $\odot$ (Reglstered trademark of the Kevex Corporation) $x$-ray fluorescence spectrometer as a front end to a Canberra counter-scaler system to analyze the spectrum produced by a radioactive cadmium-109 source when the fuel tube wall is placed at the detector. 1

Previously, a preset indexer and stepping motor were used to rotate the tubes to a specific position. The index has been replaced with a computer-controlled translator. A manual control for a synchronous induction motor was used to position the tubes longitudinally. The control and synchronous motor were replaced with a stepping motor and translator.

The Canberra counter and scalers, and the Kevex ${ }^{\circledR}$ ratemeter used in the measuring analyses were connected to the microcomputer so it could read the data directly for calculations. The cadmium109 source probe, which rides a controlled vertical elevator, was also integrated with the computer to allow the probe to be raised while the fuel tubes were rotated.

\section{CLADDING THICKNESS TESTER - SRL/6800 MICROCOMPUTER}

The photograph in Figure 1 shows the CTT on the floor of the Fabrication Development Laboratory. The SRL/6800 microcomputer and Kevex ${ }^{3}$-ray fluorescence spectrometer are in the rack beside the middle of the CTT bed. The probe elevator raises and lowers the liquid nitrogen Dewar at the left end of the CTT bed. The cadmium-109 probe source is in the plastic cage at the CTT bed's mid-section. The CTT chuck cart positions the fuel tube that is being analyzed. 


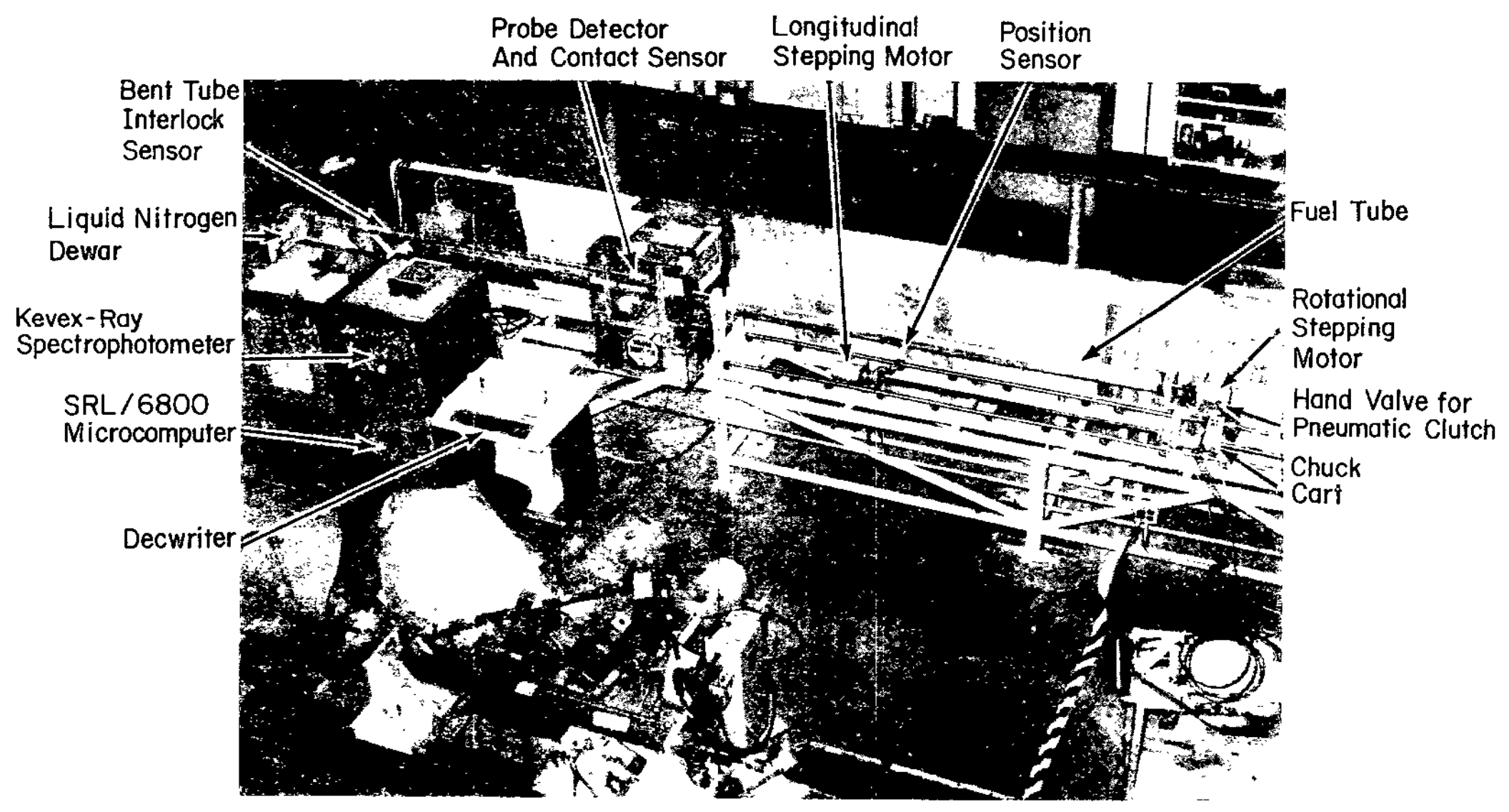

FIGURE 1. Cladding Thickness Tester 


\section{Softwere}

The characteristics of the CTT-SRL/6800 microcomputer ${ }^{2}$ are defined by its software. Four types of analyses are available in this system:

Type 1 - The core end analysis is a rather extensive routina which can search an area to find a minimum cladding thickneos point. It requires nine orientation specifications to define the search detalls. The first step in the analysis is to determine the starting position of the search with respect to an area of nominal cladding thickness. The fuel tube is then searched long1tudinaliy for a thin cladding area using a coarse scan grid, and a fine scan grid is used to pinpoint the minimum cladding thickness. The coarse grid scan is then resumed, and after a specified length of nominal thickness cladding is scanned, the fuel tube is rotated and the process repeated.

Type 2 - The ring section analysis simply rotates the fuel tube in increments, taking cladding thickness measurements at specified intervals.

Typo 3 - The spot analysis allows the detector to be centered over a spot on the fuel tube, where cladding thickness measurements are taken from a grid surrounding the center point.

Type 4 - Manual control software allows the fuel. tube to be positioned at the operator's discretion. Cladding thickness measurements can be taken as desired. Manual control is al so used to input orientation specifications for the first three analyses, and also to input constants for calculating the cladding thickness. Figure 2 is a sample of a specification entry page. Manual control software allows the option to use constants and specifications previously entered or to enter new constants and orlentation. specifications, reducing unnecessary variable entry.

The data that the microcomputer recelves from the analyses are used in an equation to determine the cladding thickness (CT equation, Figure 1)。 For three ranges of welght percent radioactive material in aluminum alloy, three different sets of constants are al so used.

$$
\begin{array}{ll}
10 \leq \% \leq 30 & \text { Constants A } \\
30<\%<50 & \text { Constants B } \\
50 \leq \% \leq 80 & \text { Constants C }
\end{array}
$$

Data are displayed in tabular form, providing coordinate information with respect to the analysis starting point, raw spectrometer data, and calculated cladding thickness (Figure 3). If the difference of count minus background for either the $L_{\alpha}$ 


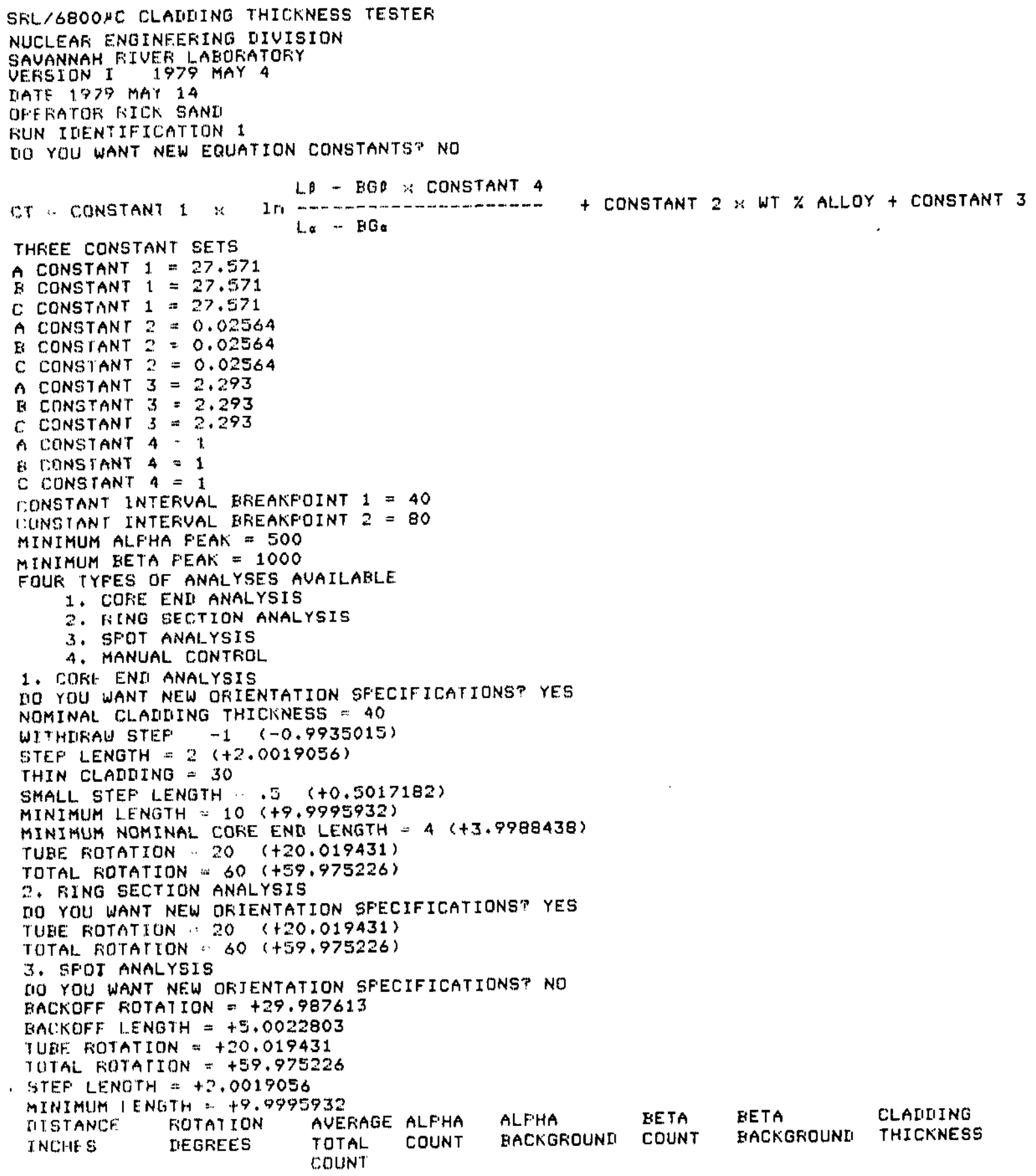

RTGU:E 2. Spectficerion Jntry 
WI HIII: $\because$ II I IIY 70

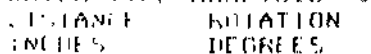

TOTAL COUN
$+0.60^{\circ}$
COISNT

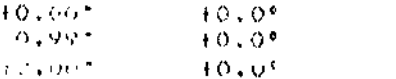

$+4.00^{\circ}+10.0$

$+1.00$

$+.00^{\circ}+0.0^{\circ}$

$10, \ldots+\quad+0.0^{\circ}$

$\because .00 \%+20.00$

$0.290 \quad+20.06$

I. $0^{\circ} \quad 1,1 \% .0^{\circ}$

$+4.1100 .00$

$10.000^{\circ} \quad 1.0 .0^{\circ}$

$+8.11,00.120$

$+10.0 .10+20.0$

$+0.00^{\circ} \quad+40.0^{\circ}$

$+2.00^{\circ} \quad+40.0^{\circ}$

$+4.300^{\circ}+40.0^{\circ}$

$+40.0^{\circ}$

$13.00^{\circ}+140.0^{\circ}$

$+10.00^{\circ} \quad+40.0^{\circ}$

$\begin{array}{ll}+0.00^{\circ} & +60.06 \\ 10.00^{\circ} & +60.06\end{array}$

$+4.00^{\circ}+60.0^{\circ}$

$+6.00^{\circ} \quad+60.00$

$+6.00^{\circ} .+60.0^{\circ}$

$.000 \quad .668$

1892

30.35

$1996 \quad 3976$

$1970 \quad 2825$

$2024 \quad 3898$

.021 3109

(1) $1.3 \quad .961$

$2024 \quad .984$

1974

1858

.027

$\therefore 136$

j01

:014

3340

$1994 \quad 3847$

$2027 \quad 3005$

1915

2056

2022

.3031

1984

$? 025$

1817

$204 \%$

.032

$200 ?$

981

711

3227

3211

3060

2.663
2704

2704

3257

3396

2765

$+60.0^{\circ}$

2746

i. COFIE FNH ANALYSIS FIUN COMFIETI

2703

WE IGHT $\because$ ALLOOY 70

WHTCH TYFE ANAL YSIS? 2

TTCTANCF ROCTATI

INCHES IIELSEEES

AUERAGE ALFHA

TOTAL. C:DUNT

COUNT

$+0.00^{\circ}+10.0^{\circ} \quad 1981 \quad 2823$

$\begin{array}{llll}10.00^{\circ}+20.0^{\circ} & 1973 & 2599\end{array}$

$+0.00^{\circ}+40.0^{\circ}+2022 \quad 2908$

$+0.00^{\circ}+60.0^{\circ} \quad 2020 \quad 3080$

2. FING SECTION ANALYSIS FIUN COMFLETE

WE.IGHT \% ALLOY $=10$

WHICH TYFEE ANALYYSIS? ,3

IITTANCE

AUEFFAGE ALFHA TOTAL C.OUNT
COUNT

$2000 \quad 2937$

$2005 \quad 3281$

3281

$+0.00$

$+0.0^{\circ}+2000$

2003

2002

1.985

3059

2577

$+2.00^{\circ}$

$+0.0^{\circ}$

$+20.0^{\circ}$

$+2.00^{\circ}$

$+40.0^{\circ} \quad 1986$

2849

3085

$1953 \quad 2863$

2471

$+4.00^{\prime \prime}$

$+4.00^{\prime \prime}$

$+0.0^{\circ}$

1949

3030

$+4.00^{\circ}$

$+20.0^{\circ}$

2008

2001

2908

3232

$2001 \quad 2814$

$+6.00^{\circ}+60.0^{\circ}$

$+6.00^{\prime \prime}+20.0^{\circ}$

$+6.00^{\circ} \quad+40.0^{\circ}$

$+6.00^{\circ}+60.0^{\circ}$

$+8.00^{\circ}+0.0^{\circ}$

$+8.00^{\circ}+20.0^{\circ}$

$+8.00^{\circ}+40.0^{\circ}$

$+8.00^{\circ}+60.0^{\circ}$

$+10.00^{\circ}+0.0^{\circ}$

$+10.00^{\circ}+20.0^{\circ}$

$+10.00^{\circ} \quad+40.0^{\circ}$

$+10.00^{\circ}$

$+60.0^{\circ}$

$1981 \quad 271$

19812685

$1996 \quad 2908$

$1990 \quad 2900$

$1983 \quad 2741$

$1987 \quad 2725$

$1947 \quad 2998$

$2007 \quad 2944$

$1940 \quad 2649$

$1965 \quad 2926$

$1953 \quad 3060$

ALFHA

$\begin{array}{lll}\text { AL.FHA } & \text { BETA } & \text { BETA } \\ \text { BACAGECBUND } & \text { COIJNT } \\ & \end{array}$

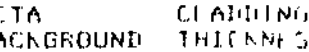

$\begin{array}{lll}568 & 9224 & 234 \%\end{array}$

$489 \quad 2630$

$53: 980$

$740 \quad 8591$

$497 \quad 8815$

$544 \quad 8859$

$966 \quad 9038$

$\therefore 48 \quad 9006$

515

$489 \quad 2629$

$598 \quad 9599$

$.93 \quad 9544$

56?

23

543

505
505

545

557

551

509

482

569

513

542

300

$2014+308$

$+37.12$

$201+31.3$

$300+33.3$

$+3.2$

$2330+360$

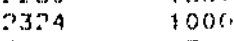

$2116+31$.

$391+32$

$2118+33.3$

?21 +32.

2.2. $3+32.1$

23131000

$.176+31.2$

$2220+31.3$

$2164+3 ? .3$

$2134+34.9$

$2143+33.1$

$2708 \quad 1000$

$3255+32.7$

$.172+30.2$

$2112+34.3$

$2201+33.5$

$2140+33 . \%$

ALPHA EETA BETA CLAIIIING

BACKGFOUNI COUNT BACKGFIOUNII THICANESS

$\begin{array}{llll}553 & 8598 & 2183 & +32 . i \\ 520 & 8361 & 2217 & +33.9 \\ 547 & 8862 & 2212 & +32.6 \\ 594 & 9077 & 2133 & +32.4\end{array}$

CLAIIIING

$564 \quad 9058$

$\begin{array}{ll}571 & 9304 \\ 529 & 9485\end{array}$

$\begin{array}{ll}529 & 9485 \\ 517 & 9122\end{array}$

1927

$550 \quad 8957$

$508 \quad 9214$

$523 \quad 8973$

$495 \quad 8262$

$548 \quad 9350$

$550 \quad 8879$

$532 \quad 9584$

$536 \quad 8655$

$531 \quad 8562$

$562 \quad 8439$

$545 \quad 8673$

$516 \quad 8713$

$617 \quad 8582$

$526 \quad 8473$

$588 \quad 9078$

$539-8919$

$560 \quad 8374$

565

8781
9018

2211

$+33.3$

$+30.8$

$2101+31.2$

$2115+32.0$

$2141+34.3$

$2183+33,8$

$2177+31.7$

$2253+33.1$

$2195+35.0$

$2191+33.2$

$2206+32.7$

$2185+31.8$

$2071+33.3$

$2184+33.6$

$2170+33.9$

$2070+32.4$

$2186+31.9$

$2224+34.3$

$2127+33.3$

$2187+33.0$

$2210+32.3$

$2132+34.2$

$2179+32.4$

3 . BFOT ANAL YSIS: FIUN COMF'LETE

WEIGHT \% ALLOY " 70

WH]CH TYFE ANALYSS[S' 4

4. MANUAL CONTFIOL.

DISTANCE FOTATION

INCHES TIEGFEES

AUE.KAGE ALF'HA

TOTAL COUNT

AL. F'HA

BETA

BE.TA

CLAIIIING COUNT

BACKGROUNI COUNT

EACKGKOLIND

THICKNESS

FIGURE 3. Data Output 
peak or the $L_{\beta}$ peak of the detected $x$-rays is below a given value, the cladding thickness value is forced to $1000 \mathrm{mils}$ in order to flag an invalid result and to allow proper program functioning.

\section{Cxt Program Structure}

The CTT program structure is centered around three analyses and the manual control option (see Figure 4) with numerical operations based on variables represented by ASCII coded characters. This allows operator-orlented input and output to be stored in. immediately useable form. The only binary operation performed is for the steppling motor handlex routine, which requires a 16-bit binary number to indicate the number of steps to move the stepping motor.

Interface and terminal initializations are actuated by a button on the CTT panel. The CTT routine then requests the alloy weight percent and the analysis that is to be run.

General practice after a power up start is to run Type 4 manual control to permit entry of equation constants and orientation specifications.

Longltudinal position sensors are actuated if the CTT chuck cart holding the fuel tube reaches either end of the CTT bed. Th1s action forces the microcomputer to restart the program, thus halifing any computer-1nitiated motion directives.

\section{Tratosero}

The microcomputer interfaced with the CTT uses three 4K EPROM modules to hold the program and messages. One 4R RAM is used for variable storage. One 4-port serial interface 18 used to drive the stepping motor translators, and one serial interface is used to communicate with a DEC ${ }^{\otimes}$ writer II terminal。 One 4R EPROM module is used for the $1 \mathrm{~K}$ monttor, and one $1 \mathrm{~K}$ RAM module is used for monttor scratch and diagnostic programs. One MPU module and one status indicator module also are used. Numerical processing is performed by a Number Cruncher module. Interfacing to the Kevex ratemeter, Canberra scaler-counters, tube handler position sensors, and probe elevator is through a Parallel Interface module.

( $\triangle \mathrm{BEC}$ is a registered trandmark of the Original Equipment Corporation. 


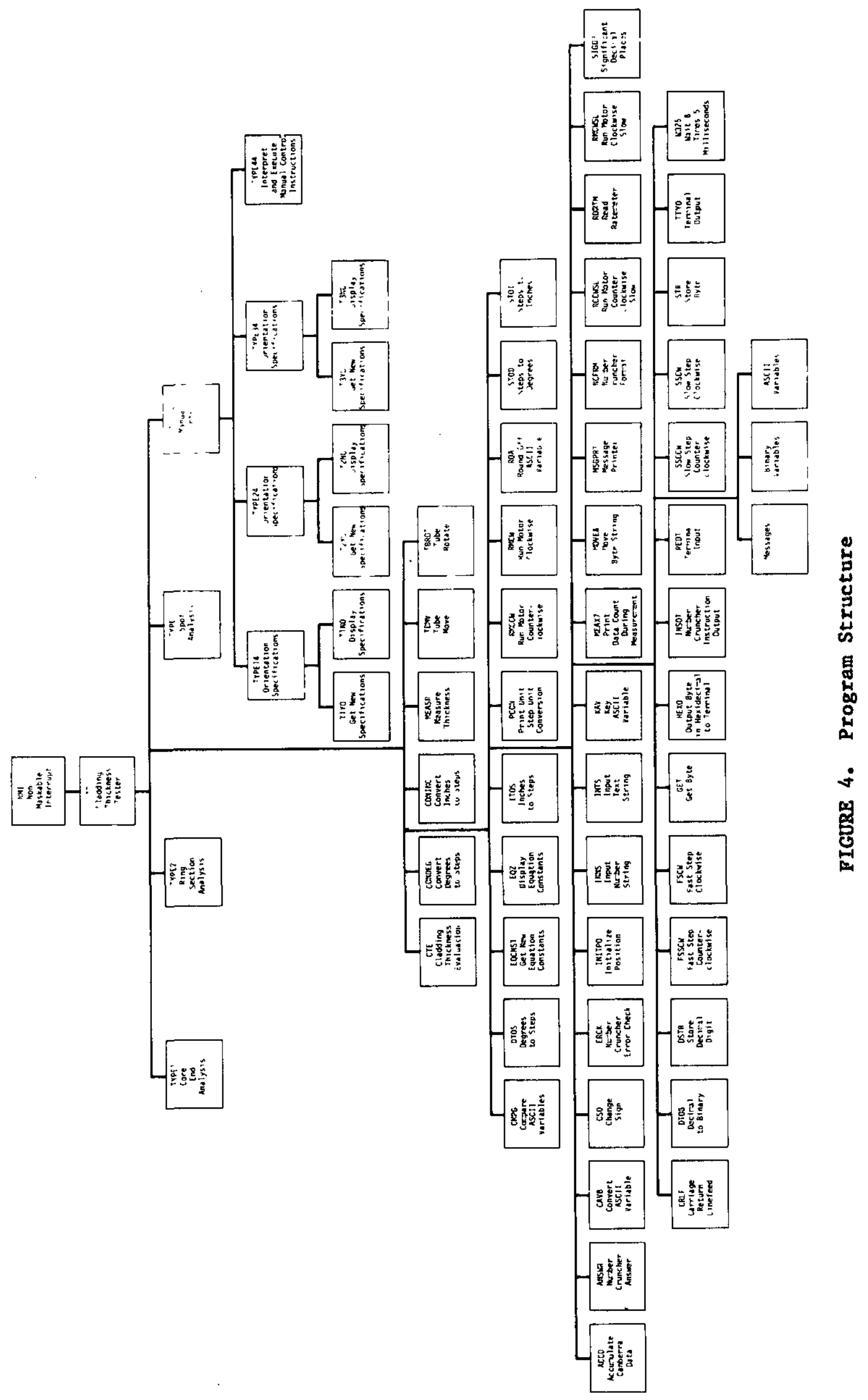




\section{REFERENCES}

1. R. V. Slates and W. E. Steward. Messurement of Reactor Tube Ciadding Thtckness by X-ray Fluorescence Spectronerry, DP-1465; Savannah River Laboratory, Atken, SC (1978)。

2. R. J. Sand, Savannah Rver Laboretory/6800 Microcompufer Herdwaxe MenwaI, DPSTM-DC-1, Savannah River Laboratory, . Aiken, SC (1979). 